\title{
Effects of water immersion ageing on composites made of non-dry flax fibres
}

\author{
Maria Morissa Lu ${ }^{\mathrm{a}, \mathrm{b}, *}$, Aart Willem Van Vuure ${ }^{\mathrm{a}}$ \\ ${ }^{a}$ KU Leuven, Department of Materials Engineering, Kasteelpark Arenberg 44, 3001 Leuven, Belgium \\ ${ }^{b}$ University of the Philippines Los Baños, Department of Engineering Science, College of Engineering and Agro-Industrial Technology, 4031 \\ Laguna, Philippines
}

\begin{abstract}
This study was performed to evaluate the effect of water immersion ageing on flexural and water sorption properties of composites made of non-dry flax fibres (conditioned at 50\% and $80 \%$ relative humidities) and resins that have low sensitivity to water. The experimental results showed that throughout the ageing study, composites made of non-dry fibre have lower moisture sorption and better flexural properties compared to composites made of dried fibre.
\end{abstract}

Keywords: flax fibres; water immersion; polymer-matrix composites; moisture; mechanical properties

\section{Introduction}

Natural fibre composites (NFC) present some advantages compared with composites made of synthetic fibres such as potentially lower material cost, lower density, and good specific strength and stiffness [1,2]. Despite the environmental and technical benefits of NFC, their use and applications have been limited due to their lower durability when compared to synthetic fibre composites, especially in outdoor conditions with high moisture content. Therefore, many recent studies focus on the feasibility of lowering NFC sensitivity to moisture to prevent its degradation.

It is common practice when manufacturing NFC that the fibres are first dried or conditioned before use. This is done to remove or control moisture which can result in voids and poor fibre-matrix adhesion [3]. The disadvantage of using dried fibres as reinforcement in composites is when the composites are subjected to high moisture environment; the composites will definitely sorb water which could cause degradation of the composites. Water sorption leads to the swelling of NFC, forming voids and microcracks at the fibre-matrix interface region which may result in a reduction of the mechanical properties and dimensional stability of the composites [4]. In literature, several authors have studied the effects of water immersion ageing on natural fibre composites made of dried fibre. Hemp/polyester composites degraded both in terms of tensile and flexural properties when the composites sorbed water molecules [5]. Tensile properties of sisal/PP composites decreased with water uptake, time of immersion and fibre loading [6]. Water sorption of kenaf fibre reinforced polyester composite laminates increased with fibre volume fraction and caused the length, width and thickness of the laminates to increase [3].

To enhance the water-resistant property of composites, this study used non-dry flax fibre and resins that have low sensitivity to moisture in the production of composites $[7,8]$ to take advantage of the moisture present in the fibre. The hypothesis to be tested is that, since the fibre already contains some water and is thus pre-swollen, the swelling of the composite due to water sorption could be limited, slowing its degradation and thereby improving its water durability. However, the presence of water in plant fibres is a concern when they are being considered for polymer reinforcement since most composites manufacturing processes involve steps at high temperatures which cause evaporation of the absorbed water in the fibre and could initiate defects such as porosity in the composites [9]. Therefore, the evaporation of water in non-dry fibre should be inhibited during the manufacturing of composites.

\footnotetext{
* Corresponding author. Tel.: +32 16374546

E-mail address: mariamorissa.lu@kuleuven.be
} 


\section{Experimental procedure}

\subsection{Materials}

The material used in this study was untreated flax fibre (Flax Tape 200, Lineo). Unsaturated polyester resin (Synolite 1967-N-1, DSM) with peroxide curing agent (Butanox M-50, Nouryon), accelerator (Nouryact CF-32, Nouryon) and an inhibitor (NLC-10, Nouryon) was used for the matrix of the composite. The other matrix used in the study was epoxy resin (Epikote $828 \mathrm{LV}$ ) with Vestamin ${ }^{\circledR}$ IPD hardener from Evonik. The Nouryact accelerator for polyester cure and Vestamin ${ }^{\circledR}$ IPD hardener have both low sensitivity to moisture.

\subsection{Composite preparation}

In order to study the effects of using non-dry flax fibre and less water-sensitive resins on water immersion ageing of composites, three kinds of epoxy/flax and polyester/flax composites were prepared for comparison; composite made from dried fibre (oven-dried at $80{ }^{\circ} \mathrm{C}$ to constant mass), composite made of non-dry fibre (fibre conditioned at $50 \%$ $\mathrm{RH}$ ) and composite made of non-dry fibre (fibre conditioned at $80 \% \mathrm{RH}$ ). The composites have a fibre volume fraction $\sim 35 \%$ and were made using vacuum-assisted resin infusion technique.

A vacuum of 0.6 bar was applied to the infusion process that was performed at ambient temperature. After the fibre was completely impregnated with the resin, the polyester/flax composite was post-cured at room temperature for 24 $\mathrm{h}$ followed by oven drying at $70{ }^{\circ} \mathrm{C}$ for $12 \mathrm{~h}$. Epoxy/flax composite was cured on hot plate at $70{ }^{\circ} \mathrm{C}$ for $4 \mathrm{~h}$ and post cured at $150^{\circ} \mathrm{C}$ for $1 \mathrm{~h}$ in a hot press using 15 bar pressure to prevent the evaporation of sorbed water in the fibre. A glass/epoxy composite was used as a benchmark in this study.

\subsection{Water immersion test}

Before the ageing study, the samples were pre-conditioned at $22{ }^{\circ} \mathrm{C}$ and $50 \% \mathrm{RH}$, which is the average Benelux standard indoor condition as well as the international standard laboratory environment, for approximately 35 days. The samples were immersed in distilled water at $20 \pm 1{ }^{\circ} \mathrm{C}$ for a total of 30 days. The weight of the samples was measured periodically and the percentages of water sorption were calculated throughout the ageing study. Samples taken out of the water were wiped to remove the surface water and then re-submerged for continued ageing. After the ageing experiment, the samples were placed in the conditioned room at $22{ }^{\circ} \mathrm{C}$ and $50 \% \mathrm{RH}$ for at least 3 weeks prior to mechanical testing. The water immersion test was conducted in the study to simulate composites fully exposed to outdoor conditions, wherein the composites are in contact with water for a long period of time. This can be considered as a relatively harsh exposure.

\subsection{Three-point bending test}

Three-point bending tests on transverse fibre-oriented composites were performed in accordance with ASTM D790 standard on a $60 \mathrm{~mm} \times 12.7 \mathrm{~mm}$ sample, with a test span of $32 \mathrm{~mm}$. A universal testing machine (Instron 5567) with a $1 \mathrm{kN}$ load cell and cross-head speed of $0.85 \mathrm{~mm} / \mathrm{min}$ were used in the study. All tests on aged samples were performed after conditioning for 30 days in the standard conditioned room. Unaged samples were also tested to compare the obtained mechanical test results with those of aged materials.

\section{Results and Discussions}

\subsection{Water uptake}

The results are presented with a composite coding system: PDT/ PT50/ PT80 are composites made of polyester and dried fibre/ fibre conditioned at 50\% RH/ fibre conditioned at $80 \% \mathrm{RH}$ in transverse fibre orientation, whereas EDT/ ET50/ ET80 are composites made of epoxy and dried fibre/ fibre conditioned at 50\% RH/ fibre conditioned at $80 \%$ 
RH in transverse fibre orientation.

The water sorption of the composites is presented in Fig. 1. The graph is constructed so that the moisture content of samples after conditioning at $22{ }^{\circ} \mathrm{C}$ and $50 \% \mathrm{RH}$ for approximately 35 days are shown as zero water sorption. Water sorption of the composites increased rapidly in the first ten days and then almost levelled-off. Glass/epoxy composite is known for being hydrophobic in nature and therefore, the composite has negligible water sorption. Reasonably, it can be observed that composites made of non-dry fibre have considerably lower water sorption properties than composites made of dried fibre for both polyester/flax and epoxy/flax composites. The results show that moisture sorption of composites decreased as the RH value for conditioning the fibres increased.

\section{(Insert Fig. 1)}

Fig. 1. Water sorption of composite samples.

The maximum moisture sorption values of PDT, PT50 and PT 80 are $8.8 \%, 7.7 \%$ and $6.7 \%$ while for EDT, ET50 and ET 80 these values are $9.1 \%, 7.0 \%$ and $6.1 \%$ respectively. Saturation was reached for all composite samples. The lower water sorption of composites made of non-dry fibre could be related to the higher water content of composites at the start of the ageing study. Possibly, a greater part of the hydrophilic groups of fibres are already occupied by water and therefore the composites can only accommodate lesser amount of water compared to composites made of dried fibre.

\subsection{Flexural strength}

Fig. 2 shows the flexural strength properties of composites throughout the water immersion ageing, after reconditioning to standard conditions. The results show that composites made of non-dry fibre have considerably better mean strength properties than composites made of dried fibre for both polyester/flax and epoxy/flax composites. It is observed that PT80 and ET80 have the highest mean strength for polyester/flax and epoxy/flax composites respectively throughout the ageing study. The lowest mean strengths for polyester/flax and epoxy/flax composites are found for PDT and EDT respectively. It is also evident that the mean strength of epoxy/flax composites was higher compared to polyester/flax composites.

At the end of the immersion test, the flexural strength of PDT, PT50 and PT 80 decreased by $41 \%, 39 \%$ and $33 \%$ while for EDT, ET50 and ET80 these values are 29\%, 28\% and 20\% respectively. But remarkably, the initial strength of the EDT sample was the lowest of the epoxy samples, followed by the ET50 sample and the ET80 sample being the strongest. It is hypothesized that the dried epoxy samples may already have some micro-damage after conditioning to standard environmental conditions before testing, before any ageing has been done. The mean strength of all composites decreased significantly starting day 1 of the immersion test. The decrease in mean strength of composites is likely due to the swelling of the flax fibres when moisture penetrates into them, forming voids and microcracks at the fibre-matrix interface region which may result in deterioration of the mechanical properties and dimensional stability of the composites [4].

The use of non-dry fibre and resins that have low sensitivity to moisture showed relevant results and thus must be considered when making composites. However, we observed that using vacuum-assisted resin infusion, the moisture in non-dry fibres somewhat influences the flow of the resin through the fibres. The moisture slows down the impregnation process which could result to incomplete impregnation of the laminate when the resin has high viscosity. Moreover, some of the resins available in the market are moisture-sensitive and therefore incompatible to be used with non-dry fibres. Therefore, in these cases, the use of at least partially dried fibres is unavoidable.

(Insert Fig. 2)

Fig. 2. Mean transverse bending strength of composites during water immersion ageing, after re-conditioning to standard conditions. 


\section{Conclusions}

Composites made of non-dry fibre have considerably lower water sorption and better transverse flexural strength properties than composites made of dried fibre for both polyester/flax and epoxy/flax composites. The results suggest that composites made of non-dry fibre and resins that have low sensitivity to moisture could be used for enhancing the water durability of NFCs.

\section{Acknowledgements}

The authors would like to acknowledge the financial support of the EU-H2020 BBI project "SSUCHY" [grant number 744349]; and The University of the Philippines, Philippines - PhD and Master's Fellowship Program for Faculty and REPS.

\section{References}

[1] R. Burgueño, M.J. Quagliata, G.M. Mehta, A.K. Mohanty, M. Misra, L.T. Drzal, J. Polym. Environ. 13 (2005) 39-49.

[2] A.K. Mohanty, M. Misra, L.T. Drzal, Compos. Interfaces. 8 (2001) 313-343.

[3] S. Rassmann, R.G. Reid, R. Paskaramoorthy, Compos. Part A Appl. Sci. Manuf. 41 (2010) 1612-1619.

[4] M.G.A. Selvan, A. Athijayamani, Fibers Polym. 17 (2016) 104-116.

[5] H.N. Dhakal, Z.Y. Zhang, M.O.W. Richardson, Compos. Sci. Technol. 67 (2007) 1674-1683.

[6] P.V. Joseph, M.S. Rabello, L.H.C. Mattoso, K. Joseph, S. Thomas, Compos. Sci. Technol. 62 (2002) 1357-1372.

[7] C.A. Fuentes, K.W. Ting, C. Dupont-Gillain, M. Steensma, A.G. Talma, R. Zuijderduin, A.W. Van Vuure, Compos. Part A Appl. Sci. Manuf. 84 (2016) 209-215.

[8] M.M. Lu, A.W. Van Vuure, Compos. Part A Appl. Sci. Manuf. 123 (2019) 301-309.

[9] C. Baley, A. Le Duigou, A. Bourmaud, P. Davies, Compos. Part A Appl. Sci. Manuf. 43 (2012) 1226-1233. 


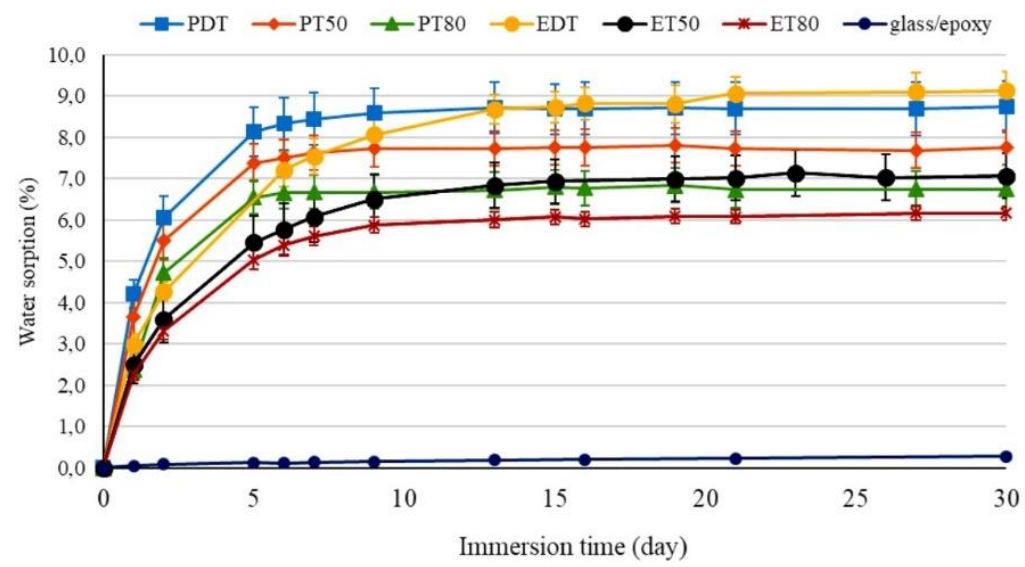

Fig. 1. Water sorption of composite samples.

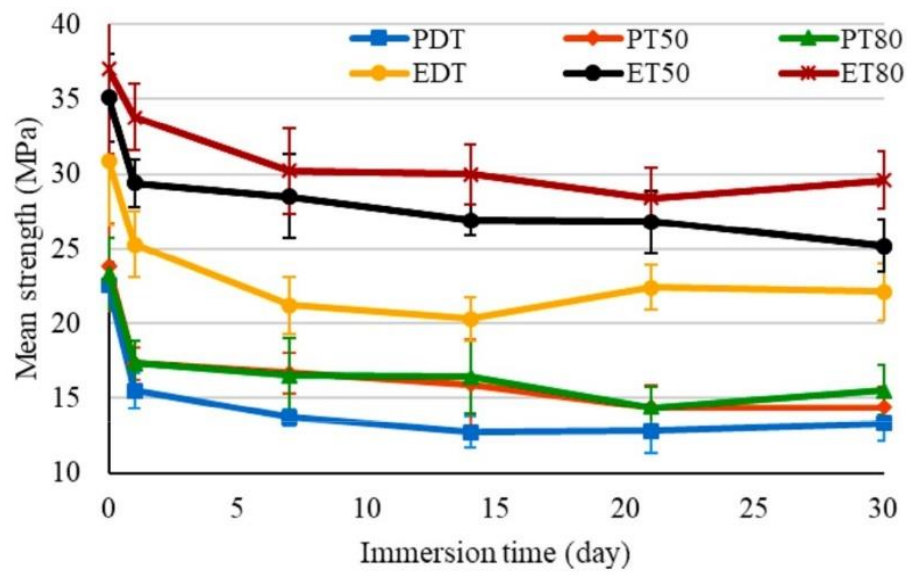

Fig. 2. Mean transverse bending strength of composites during water immersion ageing, after re-conditioning to standard conditions. 